\title{
Jellyfish and forage fish spatial overlap on the eastern Bering Sea shelf during periods of high and low jellyfish biomass
}

\author{
Mary Beth Decker ${ }^{1, *}$, Kelly L. Robinson ${ }^{2}$, Sangay Dorji $^{3}$, Kristin D. Cieciel ${ }^{4}$, \\ Caren Barceló $^{5}$, James J. Ruzicka ${ }^{6}$, Richard D. Brodeur ${ }^{7}$ \\ ${ }^{1}$ Department of Ecology \& Evolutionary Biology, Yale University, New Haven, CT 06520, USA \\ ${ }^{2}$ Department of Biology, University of Louisiana at Lafayette, Lafayette, LA 70504, USA \\ ${ }^{3}$ School of Forestry \& Environmental Studies, Yale University, New Haven, CT 06520, USA \\ ${ }^{4}$ NOAA Alaska Fisheries Science Center, Auke Bay Laboratory, Juneau, AK 99801, USA \\ ${ }^{5}$ College of Earth, Ocean, and Atmospheric Sciences, Oregon State University, Corvallis, OR 97331, USA \\ ${ }^{6}$ Hatfield Marine Science Center, Oregon State University, Newport, OR 97365, USA \\ ${ }^{7}$ NOAA Fisheries, Northwest Fisheries Science Center, Hatfield Marine Science Center, Newport, OR 97365, USA
}

\begin{abstract}
Forage fishes and scyphozoan jellyfish are both voracious planktivores within the productive eastern Bering Sea (EBS) ecosystem. To determine the potential competition between the dominant jellyfish Chrysaora melanaster and forage fishes, we compared the spatial distributions of C. melanaster and 4 forage fish species in the EBS as observed in annual surveys of the upper $30 \mathrm{~m}$. We calculated spatial metrics (centers of gravity, inertia and global index of collocation) of $C$. melanaster and each fish species and examined the degree of jellyfish-forage fish spatial overlap using several geostatistical methods during 2004 to 2012, a period that included high and low jellyfish biomass. Overall, EBS jellyfish occupied large areas where they overlapped with dominant forage fishes; however, the degree of overlap varied inter-annually with fluctuations in jellyfish and forage fish biomass and with climate conditions on the shelf. The spatial overlap between jellyfish and age-0 walleye pollock Gadus chalcogrammus was consistent in both low jellyfish biomass (2004 to 2007) and high jellyfish biomass (2009 to 2012) periods, whereas degree of jellyfish overlap with Pacific herring Clupea pallasii, capelin Mallotus villosus and age-0 Pacific cod Gadus macrocephalus varied with climate regimes. Competition between these 2 mid-trophic level groups is important because, while forage fishes are a critical link between plankton and higher trophic levels, jellyfish support few predator groups. Also, jellyfish are potential predators of the early life stages of fish. In locations where overlap is high, jellyfish predation on plankton, fish eggs and larvae may be important in driving dynamics of commercially important fish species.
\end{abstract}

KEY WORDS: Scyphomedusa $\cdot$ Planktivores $\cdot$ Spatial overlap $\cdot$ Inter-annual variability $\cdot$ Pelagic fishes

\section{INTRODUCTION}

Blooms of gelatinous plankton predators (i.e. jellyfish) are frequent occurrences in many coastal ecosystems, with some evidence of increasing populations (Brotz et al. 2012, Condon et al. 2013). Jellyfish are important consumers of zooplankton and can sig-

${ }^{*}$ Corresponding author: marybeth.decker@yale.edu

${ }^{\S}$ Advance View was available online October 23, 2017 nificantly restructure food webs when their abundance is high (Deason \& Smayda 1982, Suchman et al. 2008, Condon et al. 2011). Field studies in other ecosystems indicate that jellyfish can negatively impact fisheries because they compete with zooplanktivorous fish and feed on early life stages of fish (Purcell \& Grover 1990, Purcell \& Sturdevant 2001, restricted. Authors and original publication must be credited. 
Brodeur et al. 2008b, 2011, Shoji et al. 2009). Likewise, modeling studies have shown that jellyfish indirectly compete with other groups within the food web by diverting plankton production away from upper trophic levels (Ruzicka et al. 2012, Robinson et al. 2014, 2015, Schnedler-Meyer et al. 2016).

The eastern Bering Sea (EBS) is a biologically productive and economically valuable ecosystem, supporting rich populations of zooplankton, forage fish, groundfish, crabs, seabirds and marine mammals. The EBS ecosystem also supports large jellyfish populations. Jellyfish biomass, consisting primarily of the northern sea nettle Chrysaora melanaster, has fluctuated greatly over the past 3 decades (Brodeur et al. 2008a, Decker et al. 2014). A steep increase was documented over the EBS shelf during the 1990s (Brodeur et al. 2002). Biomass peaked in summer 2000 and then declined precipitously, stabilizing at a moderately low level between 2001 and 2008 . The onset of the biomass increase during the 1990s and the biomass decline in 2000 coincided with transitions between climatic regimes. Brodeur et al. (2008a) examined a 27 yr time series of EBS jellyfish biomass relative to physical conditions, current patterns, zooplankton biomass and associated fish biomass. These analyses indicated that jellyfish biomass fluctuations during the 1982 to 2004 period were influenced regionally by interacting variables such as sea ice cover, sea surface temperature, currents, wind mixing and prey availability.

The EBS shelf is also a highly dynamic ecosystem, forced by a variable climate and oceanographic conditions (Bond \& Adams 2002, Aydin \& Mueter 2007, Stabeno et al. 2016). The EBS ecosystem has recently experienced anomalously warm (2001 to 2005) and cold (2006 to 2012) conditions, as indicated by late summer and fall water temperatures and changes in winter sea ice conditions (Stabeno et al. 2012, Eisner et al. 2014, Sigler et al. 2016). Changes in ice conditions and timing of the spring bloom have been hypothesized to affect EBS zooplankton biomass (Hunt et al. 2011, Sigler et al. 2016). Recent ecosystem studies indicate that with the cooling that occurred between 2006 and 2010, as the system transitioned from warm to cold, populations of large zooplankton (i.e. Calanus marshallae and Thysanoessa spp.) increased (Coyle et al. 2011, Hunt et al. 2011, Eisner et al. 2014, Sigler et al. 2016). Likewise, trawl surveys between 2009 and 2012 indicate that jellyfish biomass has increased once again to late-1990 levels (Decker et al. 2014). Peaks in zooplankton biomass during the time series preceded increases in jellyfish biomass, suggesting that food availability is a key factor contributing to fluctuations in Bering Sea jellyfish populations.

Due to their high abundance and spatial overlap (e.g. Brodeur et al. 1999) with some forage fish species in the Bering Sea, there is a potential for jellyfish, and specifically C. melanaster, to negatively impact fish through direct predation upon fish eggs and larvae or through competition for resources. In other systems, research has shown jellyfish and the early life stages of commercial fish and forage fish to overlap significantly in space and time (Brodeur et al. 2008b, 2014, Eriksen et al. 2012, Eriksen 2016). In the North Sea, Lynam et al. (2005) found inverse relationships between jellyfish abundance and Atlantic herring Clupea harengus recruitment, indicating that jellyfish may have negative effects on commercial fisheries. Inverse relationships between jellyfish and forage fish biomass have also been observed in the EBS, as well as in other coastal ecosystems (Robinson et al. 2014), suggesting that jellyfish are negatively impacting age-0 fish via predation and competition. Thus, in locations where jellyfish-forage fish overlap is high, predation by jellyfish on fish and their planktonic prey may be an important factor affecting the dynamics of commercially important fishes. However, we currently lack an understanding of how EBS jellyfish affect trophic energy flow through the ecosystem and how different forage fish species are impacted.

Here, we examined the extent of spatial overlap and co-occurrence of $C$. melanaster and 4 dominant pelagic fish species: mixed age class (includes age-0 to adult) Pacific herring Clupea pallasii, mixed age class capelin Mallotus villosus, age- 0 walleye pollock Gadus chalcogrammus and age-0 Pacific cod Gadus macrocephalus during summer surveys in 2004 to 2007 and 2009 to 2012 . We examined differences in spatial overlap during periods of low (2004 to 2007) and high (2009 to 2012) jellyfish biomass, as well as inter-annual changes.

\section{MATERIALS AND METHODS}

Jellyfish and forage fish were collected on the National Marine Fisheries Service Alaska Fisheries Science Center (NMFS AFSC) Bering-Arctic Subarctic Integrated Survey (BASIS) between 2004 and 2012. These surface trawl surveys collect forage fish and large medusae from mid-August to early October. The sampling grid covered the shelf off western Alaska, from 160 to $172^{\circ} \mathrm{W}$ longitude and 55 to $64^{\circ} \mathrm{N}$ latitude (Fig. 1). All stations were approxi- 


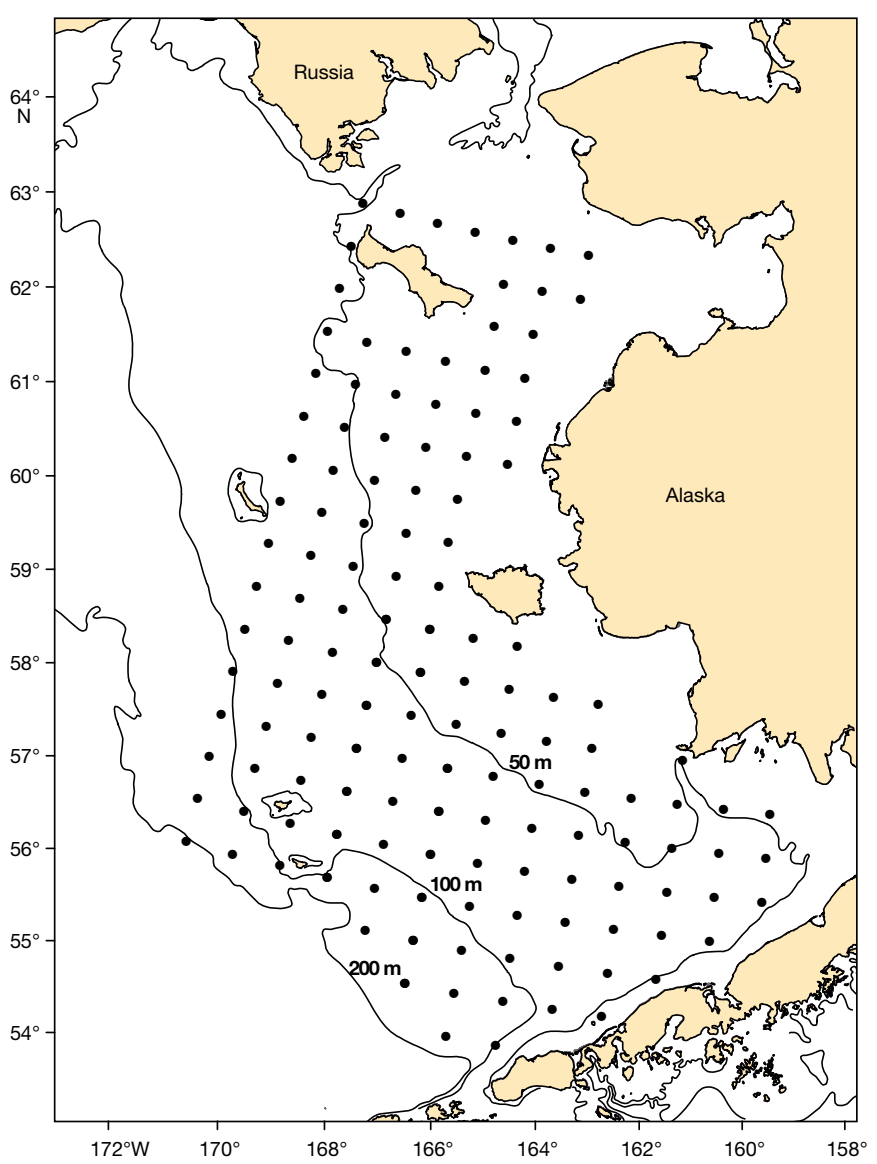

Fig. 1. Eastern Bering Sea Bering-Arctic Subarctic Integrated Survey (BASIS) grid for stations sampled between 2004 and 2012. The annual survey occurs during August and September and focuses on fisheries. Forage fish, jellyfish and oceanography are sampled at each station (black dots). The 50, 100 and $200 \mathrm{~m}$ bottom depths are indicated by isobath lines on the map, which also delineate the inner, middle and outer domains, respectively, in the Bering Sea

mately 30 nautical miles $(55.6 \mathrm{~km})$ apart. All tows were standardized for gear (50 m wide by $18 \mathrm{~m}$ deep) and duration of tow (30 min at 3.5 to 5 knots, covering 2.8 to $4.6 \mathrm{~km}$ ). Fish and jellyfish were collected using a Cantrawl model 400/601 (Cantrawl Pacific) midwater rope trawl, at or near the surface, with typical spreads of $66.4 \mathrm{~m}$ horizontally and $14.6 \mathrm{~m}$ vertically. Sea-surface temperatures were collected with a CTD (conductivity, temperature, depth) sensor between 0 and $10 \mathrm{~m}$. All net sampling was performed during daylight hours. We omitted the 2008 survey data from our spatial analyses, as the station coverage in 2008 differed significantly from that in the other years of our study.

Pelagic fish and jellyfish distributions are highly patchy. Pelagic trawl survey data are skewed and highly variable-most individuals may be collected within a small number of relatively large hauls while a large number of hauls may collect no individuals of a particular species. To accurately estimate annual mean biomass densities of Chrysaora melanaster and each forage fish species within the eastern Bering Sea from the BASIS pelagic trawl survey data (Fig. 1), we adopted the $\Delta$-distribution method of Pennington (1996). For each species, this method calculates the mean biomass density from a log-normal model of the non-zero hauls, weighted by the proportion of non-zero hauls among all hauls. The mean estimated using the $\Delta$-distribution method is more precise than the sample average and for large sample sizes (n > 20 ) is reasonably robust against deviations from the log-normal model (Pennington 1996).

We calculated spatial metrics (centers of gravity and inertia) to describe the distribution of the main forage fish species and $C$. melanaster yearly in the Bering Sea. Center of gravity (CG) represents the mean spatial location of the sampled population and was calculated for each species in each year. Inertia $(I)$ is the variance of the locations of positive catches (or the mean squared distance between positive catch locations) (Woillez et al. 2009). Using CG and $I$, we calculated the global index of collocation (GIC) between a given forage fish species and $C$. melanaster in a given year. GIC was calculated by taking the distance between their CGs and respective $I$ values (Bez \& Rivoirard 2000, Woillez et al. 2009), ranging between 0 (no individuals of either jellyfish or forage fish species co-occurred at any survey station) and 1 (where the CG of both species were at the same location). For equations describing the calculations for CG, I and GIC, we refer the reader to Woillez et al. (2007, 2009).

Station-level overlap was measured using the Cramér-von Mises randomization test (Syrjala 1996). This is a non-parametric test of the null hypothesis that $C$. melanaster and the forage fishes have different distribution patterns for all the years of sampling. The test statistic $(\Psi)$ is calculated and compared to 9999 random permutations of both populations redistributed among the survey stations as implemented in the 'ecespa' package (De la Cruz 2008) in $\mathrm{R}$ (R Core Team 2013). This test measures differences in the way the populations are distributed in the study area but is insensitive to abundance differences between populations.

We determined the degree of spatial overlap of each forage fish species with C. melanaster using geostatistical methods following procedures described by Brodeur et al. (2008b, 2014). This was done annually and for all 4 forage fish species for all BASIS sta- 
tions. Briefly, outliers in jellyfish and fish data sets were removed by finding the maximum biomass value and replacing it with the next largest value in the data set. Biomass data were then $\log _{10}(x+1)$ transformed to improve normality. Transformed data were projected in ArcMap using the North American Datum 1983 Alaska Albers coordinate system, and tested for overall significant spatial autocorrelation using Moran's $I(\alpha=0.05)$. Geostatistical models were then fitted to each transformed jellyfish and fish species data set using the Geostatistical Analyst package (ArcGIS v.10.2; ESRI). An inverse distance weighting model was used if no overall or directional (i.e. anisotropy) spatial autocorrelation was detected; ordinary kriging models were used if spatial autocorrelation was observed. Three predictive models were generated for each data set if kriging was used. Model fit was evaluated using 4 metrics: mean error, root-mean-square-error, mean standard error, and root-mean-square standardized error, following Johnston et al. (2001). The best fitting model was used to estimate biomass in the annual survey area. The spatial extent $\left(\mathrm{km}^{2}\right)$ was then calculated for 3 biomass levels: $0,>0$, and $\geq 75^{\text {th }}$ quartile value. Overlap between jellyfish and each fish species was estimated as the area where co-occurring biomass for each taxon was greater than zero. Exceptionally high overlap was determined as areas where jellyfish and fish biomasses were both $\geq 75^{\text {th }}$ quartile values.

\section{RESULTS}

\section{Fluctuations in jellyfish and forage fish biomass}

Chrysaora melanaster biomass has varied in the AFSC surface trawl survey since their monitoring began in 2004 (Fig. 2a). Similar to what has been observed on the AFSC bottom trawl surveys (Decker et al. 2014), jellyfish biomass sampled by the surface trawl was low in the mid-2000s, but then increased after 2008.

Both jellyfish and forage fish biomass in the upper $30 \mathrm{~m}$ changed dramatically during the 2 periods we examined (2004 to 2007 and 2009 to 2012). Jellyfish biomass was uniformly low during 2004 to 2007 (Fig. 2a), which was also a time when the surface layer was relatively warm in the survey area (Fig. 3). By contrast, jellyfish biomass was variable but higher between 2009 and 2012 (Fig. 2a), a period when cool surface waters were present on the EBS shelf. Similarly, capelin Mallotus villosus biomass was higher in the later period (Fig. 2b), while biomass of age-0 walleye pollock Gadus chalcogrammus was higher during the earlier period (Fig. 2e). Age-0 Pacific cod Gadus macrocephalus and adult Pacific herring Clupea pallasii biomass was variable during both periods, but appeared to be higher during 2004 to 2007 (Fig. 2c,d).

\section{Centers of jellyfish and forage fish distributions}

Distribution of the CG and $I$ for C. melanaster and the 4 forage fishes during the 2004 to 2012 surface trawl surveys showed different spatial and temporal patterns (Fig. 4). Overall, C. melanaster was centered in the middle of the survey area, occupying the middle and inner shelf areas. During the cold year of 2012, the center of the $C$. melanaster distribution shifted to the southeastern extent of the survey area. The distribution of Pacific herring was centered inshore in the northern part of the survey, while capelin were centered in the northern middle shelf. Similar to C. melanaster, the center capelin distribution shifted to the south when conditions were cold in 2012. By contrast, walleye pollock and Pacific cod biomass was centered in the southern middle shelf.

Capelin and walleye pollock had the highest degree of overlap in most years, while herring and Pacific cod showed more moderate degrees of collocation with jellyfish (Fig. 5). Overall, the degree of overlap between jellyfish and forage fish differed in low jellyfish (2004 to 2007) and high jellyfish (2009 to 2012) periods; i.e. collocation was greater when C. melanaster biomass was low (Fig. 5).

Based upon the Cramér-von Mises randomization test (Syrjala 1996) results, the forage fish in most years (22 out of 32 combinations) had significantly overlapping distributions with C. melanaster, but there were notable exceptions (Table 1). All years except 2004 had at least one non-significant overlap; but in no year were more than half of the comparisons non-significant. Capelin and walleye pollock showed the least overlap with $C$. melanaster with half of the years showing no significant differences (Table 1).

\section{Spatial overlap of jellyfish and forage fish distributions}

Geospatial mapping revealed different patterns of overlap among $C$. melanaster and the 4 forage fish species (see Figs. 6-10). Spatial overlap between $C$. melanaster and herring was consistent in all years 


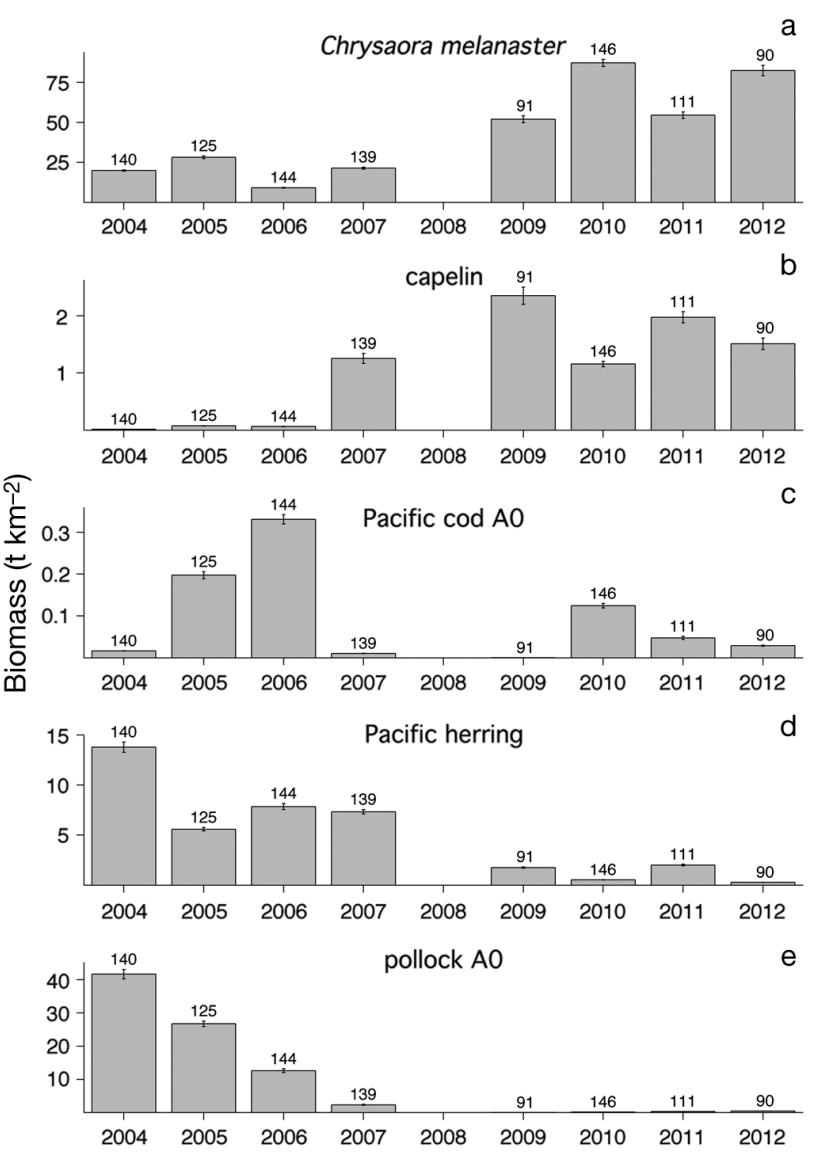

Fig. 2. Time series of mean biomass density of (a) Chrysaora melanaster, (b) capelin Mallotus villosus, (c) age-0 Pacific cod Gadus macrocephalus, (d) Pacific herring Clupea pallasii and (e) age-0 walleye pollock Gadus chalcogrammus in the eastern Bering Sea as estimated from the Bering-Arctic Subarctic Integrated Survey (BASIS) pelagic trawl data. Values above error bars (1 SE) indicate number of trawls sampled each year

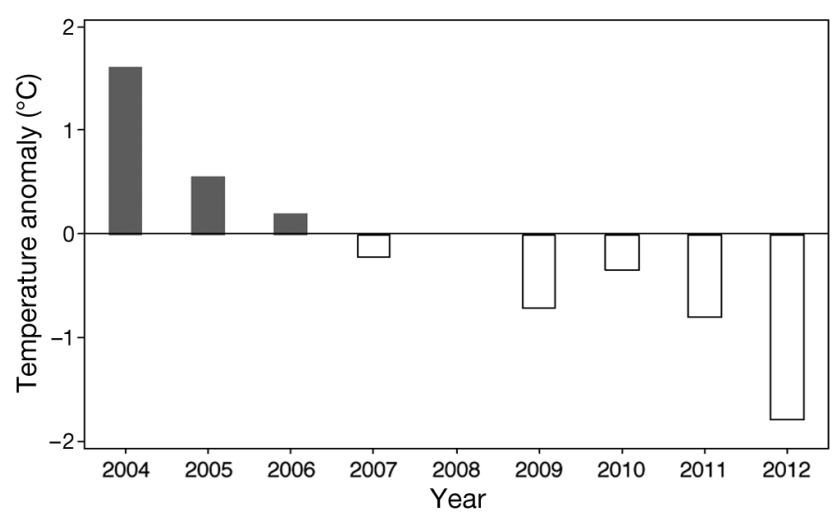

Fig. 3. Annual fall sea-surface temperature anomalies from the Bering-Arctic Subarctic Integrated Survey (BASIS) stations in the eastern Bering Sea from 2004 to 2012. Temperatures were averaged over the top $5 \mathrm{~m}$ from CTD casts and the reference value was based on August and September data from the eastern Bering Sea during 2003 to 2016. Black bars $=$ positive, white bars $=$ negative and there was no apparent difference in overlap during the 2 periods of 2004 to 2007 and 2009 to 2012 (Figs. 6 \& 7). By contrast, spatial overlap of C. melanaster and capelin changed over time. In the warm period when jellyfish biomass was low, there was a reduced area where overlap occurred (Fig. 8). The increase in jellyfish biomass that occurred between 2009 and 2012 (Fig. 2a) resulted in greater overlap of capelin and $C$. melanaster throughout the middle shelf (Fig. 8).

For both age-0 walleye pollock and age-0 Pacific cod, there were larger regions of high overlapping biomass, where both forage fish and jellyfish were in the upper 75th percentile for biomass (Figs. $9 \& 10$ ). Spatial overlap maps also revealed that walleye pollock and C. melanaster co-occurred in similar habitats, that is, primarily on the middle shelf. During the early period (2004 to 2007), Pacific cod and C. melanaster co-occurrence reached into the northern portion of the survey, whereas during the later period (2009 to 2012), the overlap between Pacific cod and C. melanaster was restricted to the southern half of the survey (Fig. 10).

\section{DISCUSSION}

The goal of this study was to estimate the scale of spatial overlap and potential for competition between forage fish and jellyfish in the EBS by determining their spatial overlap across several years. Our study on Chrysaora melanaster builds on work done in the northern California Current (NCC) on the congener C. fuscescens (Brodeur et al. 2014). Similar to Brodeur et al. (2014), we used fisheries-independent data collected over several years and varying oceanographic conditions to examine inter-annual changes in spatial overlap between a dominant jellyfish and forage fishes. Brodeur et al. (2014) found that higher interspecific spatial overlap in the NCC occurred during cool and highly productive years compared to warm years when distributions were more dissimilar. In the NCC study and in the present EBS study, the abundance of Chrysaora spp. was higher during the cooler period (2009 to 2012), allowing for a wider spatial distribution which likely increased spatial overlap with all pelagic species.

Scyphomedusa biomass on the Bering Sea shelf has fluctuated widely over the last few decades as indicated by surveys conducted for fisheries assessments (Brodeur et al. 2008a, Decker et al. 2014). Climate variability is known to be an important driver of change in the Bering Sea ecosystem. Variable envi- 

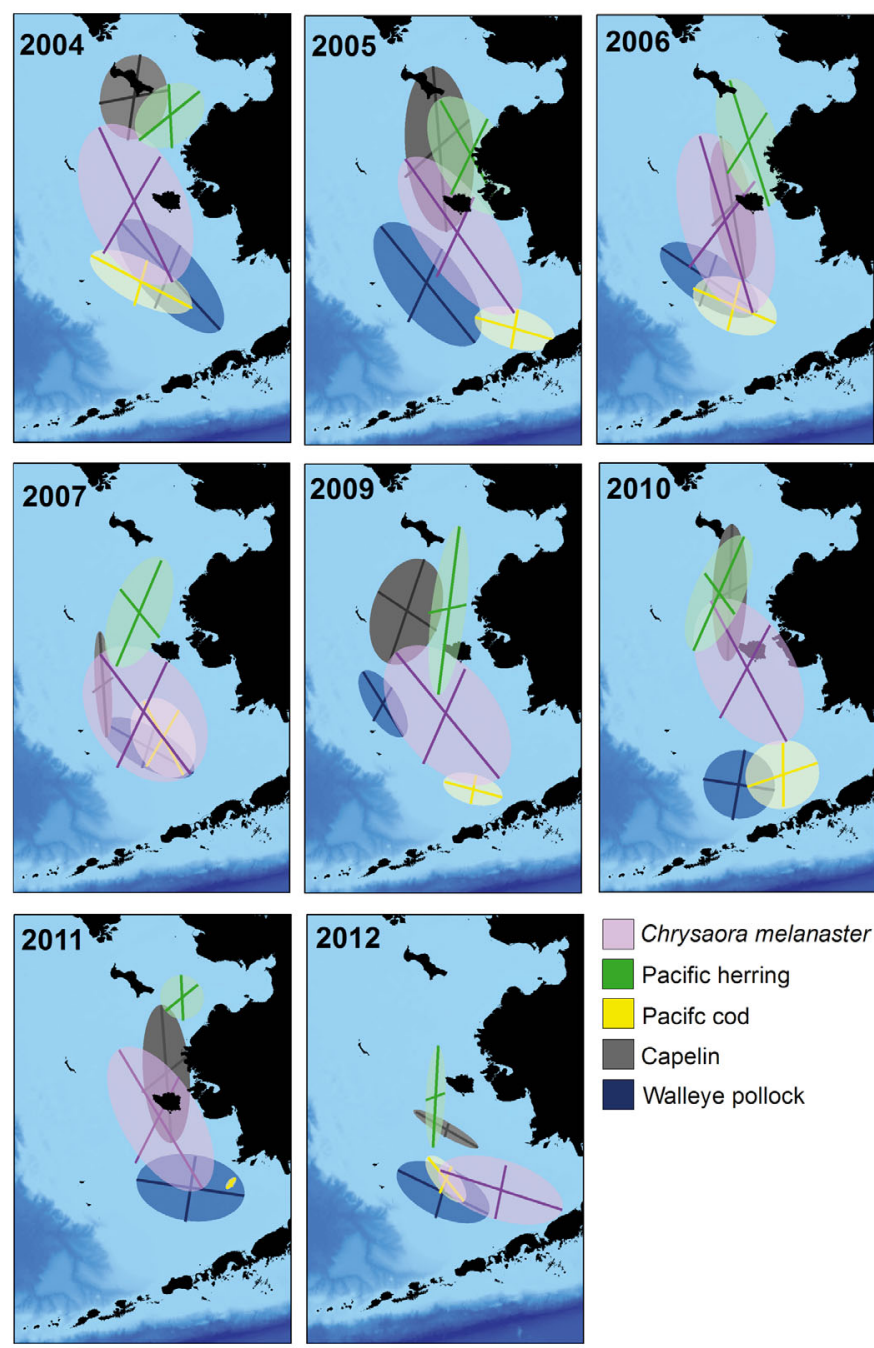

Chrysaora melanaster

Pacific herring

Pacifc cod

Capelin

Walleye pollock

Fig. 4. Distribution of the center of gravity and axes of inertia for Chrysaora melanaster and the 4 forage fishes collected during the Bering-Arctic Subarctic Integrated Survey (BASIS) survey. Color of lines and ellipses represent each species as indicated in the key ronmental conditions have been shown to affect multiple trophic levels ranging from primary producers to zooplankton including jellyfish, and up to the top trophic levels (Hunt et al. 2002, 2011, Coyle et al. 2011, Sigler et al. 2016). A simple ecosystem model indicates that high productivity and trophic control, along with fishing pressure and reduced water clarity, results in increased jellyfish biomass and a decrease in forage fish (Schnedler-Meyer et al. 2016).

When pelagic fish occur in areas where jellyfish biomass is high, they can be impacted in several ways. The most direct is through jellyfish predation on the early life stages (Möller 1984, Purcell \& Grover 1990, Purcell \& Arai 2001, Tilves et al. 2016). Although there are limited data on the diet of $C$. melanaster in the Bering Sea, the data that do exist show that they do consume early stages of walleye pollock, and thus have the potential to impact pollock recruitment due to their high densities in this region (Brodeur et al. 2002). Evidence for this is not limited to the Bering Sea; in the North Sea (Lynam et al. 2005) and the Black Sea (Oguz et al. 2008), jellyfish predation upon fish larvae and competition between fish and jellyfish for zooplankton food may have contributed to diminished fish recruitment. Jellyfish also have the potential to compete for limited prey resources with older age classes of fish when diets of jellyfish and fish overlap (Purcell \& Sturdevant 2001, Brodeur et al. 2008b, Shoji et al. 2009). Although such competition has not been demonstrated for the Bering Sea, avoidance of competition among fish species has been observed, in that early life stages of walleye pollock and

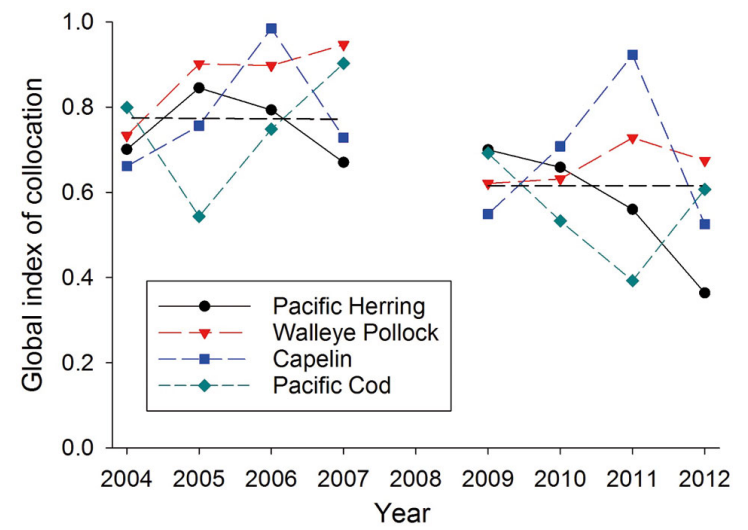

Fig. 5. Inter-annual variability of the global index of collocation (GIC) for Chrysaora melanaster and the 4 forage fishes. Dashed horizontal black lines indicate mean GIC in low jellyfish bio-mass (left) and high jellyfish biomass (right) periods
Table 1. Cramér-von Mises test p-values for the difference between the spatial distributions of Chrysaora melanaster and the 4 forage fishes. Most pairwise comparisons were significant, indicating overlap in the distributions of the jellyfish and forage fish species. Non-significant differences at $p>0.01$ and $p>0.05$ are highlighted in bold with a single and double asterisk, respectively

\begin{tabular}{|cccrc|}
\hline Year & Capelin & Pollock & Cod & Herring \\
\hline 2004 & 0.002 & $<0.001$ & $<0.001$ & $<0.001$ \\
2005 & $\mathbf{0 . 0 2 6}^{*}$ & 0.004 & 0.001 & $\mathbf{0 . 0 3 1}^{*}$ \\
2006 & $\mathbf{0 . 6 1 3}^{\text {** }}$ & $\mathbf{0 . 0 1 4}^{*}$ & $<0.001$ & 0.003 \\
2007 & 0.001 & $\mathbf{0 . 1 1 7}^{* *}$ & $<0.001$ & $<0.001$ \\
2009 & $<0.001$ & $\mathbf{0 . 0 6 4}^{\text {** }}$ & 0.003 & 0.010 \\
2010 & $\mathbf{0 . 0 1 5}^{*}$ & $<0.001$ & $<0.001$ & 0.002 \\
2011 & $\mathbf{0 . 1 1 7}^{\text {** }}$ & $\mathbf{0 . 0 1 2}^{*}$ & $<0.001$ & $<0.001$ \\
2012 & $<0.001$ & 0.006 & $\mathbf{0 . 1 0 1}^{* *}$ & 0.002 \\
\hline
\end{tabular}




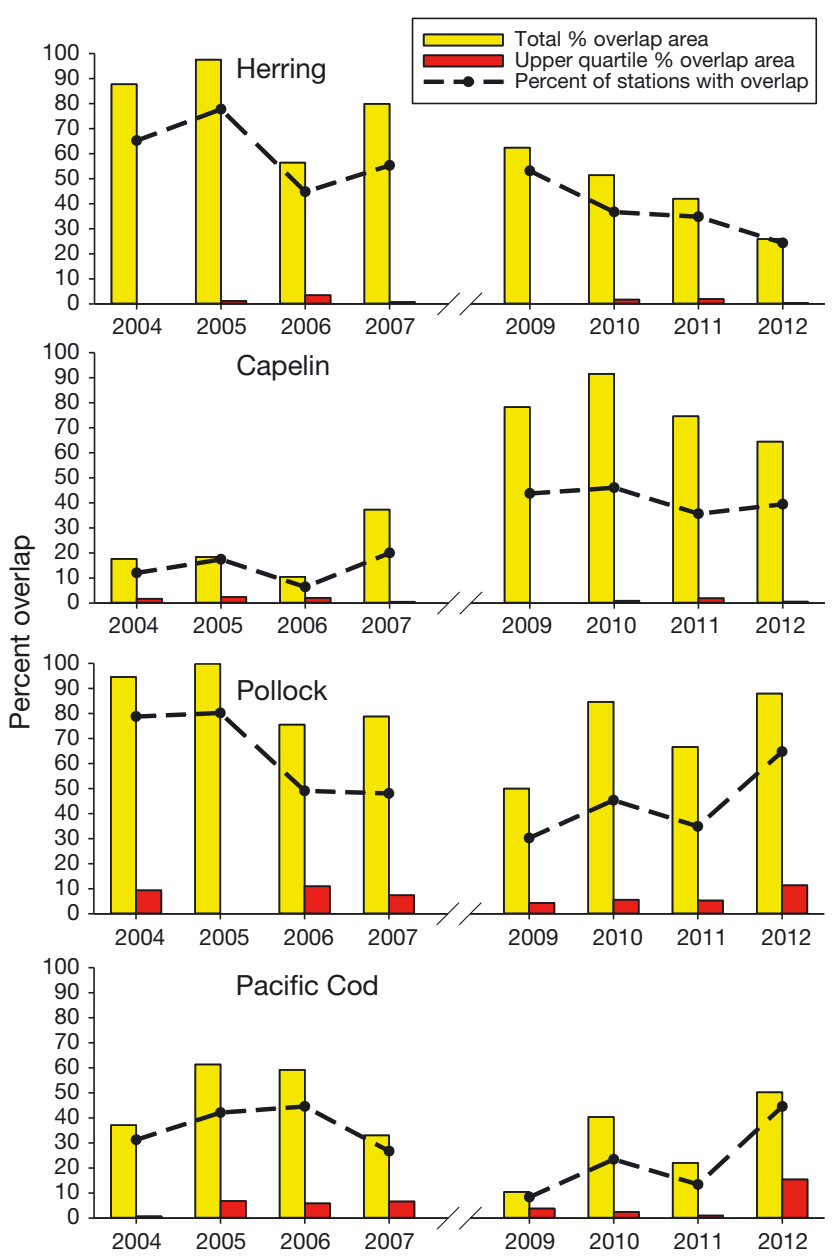

Fig. 6. Inter-annual variability of spatial overlap of Chrysaora melanaster and 4 forage fish species, based on GISinterpolated maps. Shown are the total overlap areas as a percent of the total area sampled (yellow bars), the area of overlap of the pixels containing $>75 \%$ of the biomass of both Chrysaora melanaster and forage fishes (red bars), and the total percentage of stations where overlap occurred (points and dashed lines) on each survey

Pacific cod partitioned prey resources during cold, high productivity conditions in the southeastern Bering Sea, rather than competing for them as they might during low productivity conditions (Strasburger et al. 2014). Finally, jellyfish blooms have been shown to affect commercial fisheries directly through net fouling, spoilage of the catch and limiting fishing opportunities in areas of high jellyfish abundance (Purcell et al. 2007, Kim et al. 2012, Quiñones et al. 2013, Graham et al. 2014).

Changes in overlap of jellyfish and forage fish may be driven by changes in the distributions of both groups in response to changing environmental conditions. During the cold period (2006 to 2011), capelin were distributed into the southeastern Bering Sea and were present in a large portion of the Inner and Middle Domains, whereas during the warm period (2002 to 2005), capelin were restricted to the northeastern Bering Sea (Andrews et al. 2016). In contrast, mixed-age Pacific herring Clupea pallasii catches showed less variation in the EBS during warm and cold periods (Andrews et al. 2016). Similarly, the distribution of EBS age-0 Pacific cod Gadus macrocephalus tends to be relatively stable across thermal regimes (Hurst et al. 2012, Parker-Stetter et al. 2016). Age-0 walleye pollock Gadus chalcogrammus generally occur in stratified waters of the middle domain (50 to $100 \mathrm{~m}$ depth), and they exhibit a broader geographical distribution in the surface waters during warm compared to cool periods (Hollowed et al. 2012).

During periods of high spatial overlap, forage fish may actively avoid regions of high jellyfish biomass. We saw evidence of this between 2009 and 2012, a time of increased jellyfish abundance in the survey area (Fig. 2a). That is, the mean GIC of all forage fish species was lower in 2009 to 2012 compared to the earlier period (Fig. 5). This may be an indication that the fish moved to other areas after the jellyfish became numerous. In the North Sea, an inverse correlation between jellyfish abundance and subsequent herring production may be indicative of active avoidance of herring from regions of high jellyfish abundance and movement into less favorable foraging environments (Lynam et al. 2005).

Shifts in forage fish distribution influence the degree of overlap between jellyfish and fish. We observed greater overlap between C. melanaster and capelin in cold years than in warm years (Figs. 6 \& 8). In warm years, capelin shifted to the north, away from the center of the survey area where jellyfish biomass was most concentrated. However, because Pacific herring distributions varied little in the EBS during warm and cold periods (Andrews et al. 2016), the decrease in the total overlap area of jellyfish and forage fish during 2009 to 2012 (Figs. 6 \& 7) may have been driven by herring avoidance of high jellyfish biomass regions, or indicative of low herring abundance. Likewise, while distributions of age-0 walleye pollock and age-0 Pacific cod remained similar during the 2 periods we examined (Parker-Stetter et al. 2016), the percent overlap of these 2 species with jellyfish declined during the latter period when jellyfish biomass was high (Figs. 6, $9 \& 10$ ).

The horizontal distributions of EBS jellyfish are also influenced by environmental conditions (Decker et al. 2013), especially between warm and cold years. However, fish might be more likely to respond to 
Pacific herring present $\square$ Pacific herring \& C. melanaster overlap

Pacific herring \& C. melanaster overlap (biomasses $\geq 75$ th quantile)
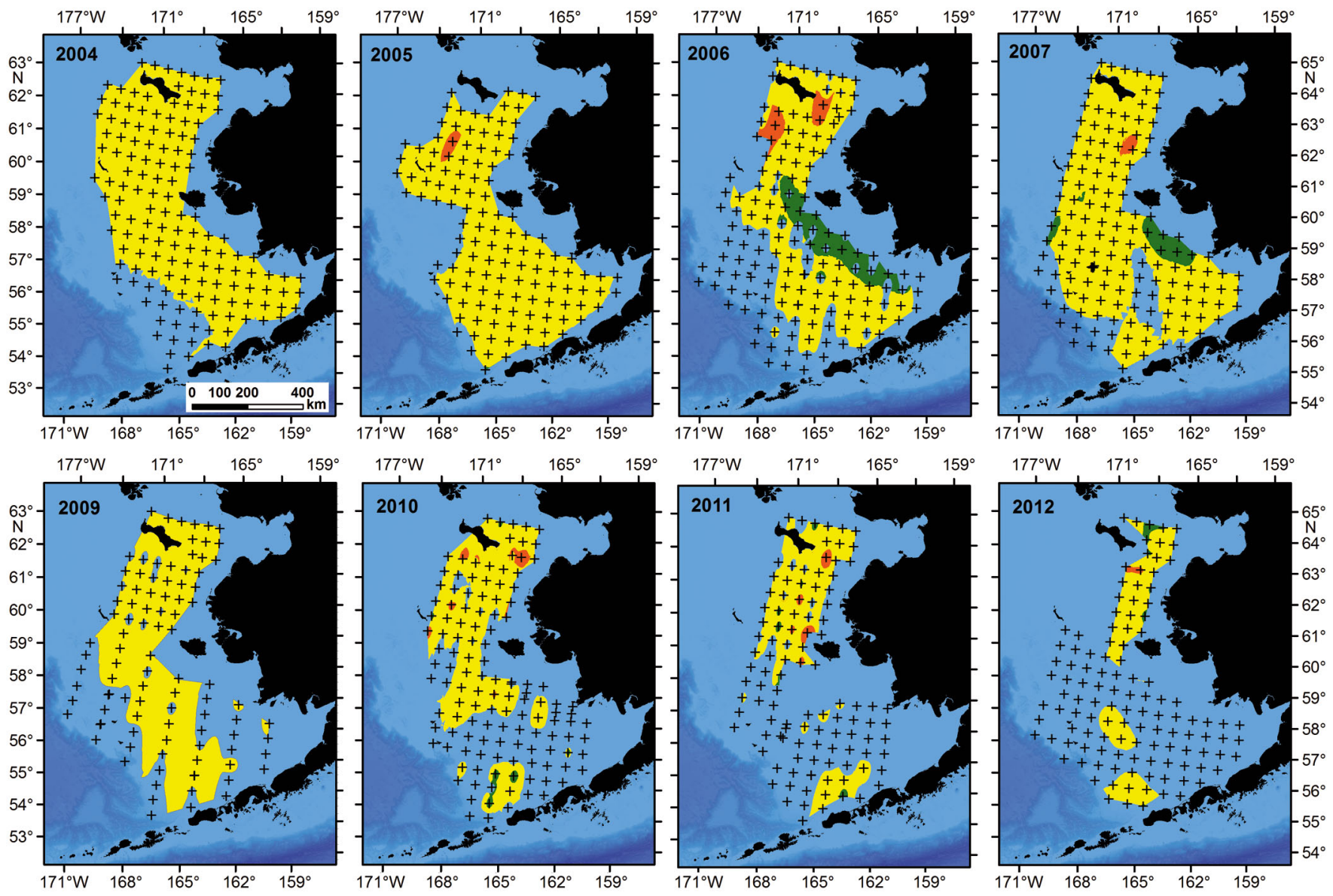

Fig. 7. Areas of no, moderate and high overlap between Chrysaora melanaster and Pacific herring Clupea pallasii. Shown are sampling stations (crosses), occurrence of herring (green area), overlap between herring and jellyfish (yellow area) and region of maximum overlap ( $>75$ th percentile of biomass of both herring and jellyfish; red area)

changing environmental conditions by moving horizontally than jellyfish, which may be constrained by the locations where their polyps occur (Chen et al. 2014) and by their more limited swimming abilities. Ocean currents in the EBS vary between warm and cold years (Stabeno et al. 2012), which may influence the degree of displacement of medusae from their benthic polyp sources, i.e. rocky coastlines in the EBS (Chen et al. 2014). Changes in winter sea ice and general ocean warming may result in poleward shifts of forage populations and their prey resources (Mueter \& Litzow 2008), but it is presently uncertain how changing conditions will affect jellyfish production or distribution in the Bering Sea (Brodeur et al. 2008a). Further studies are needed to examine how projected future changes in the physical environment could drive changes in spatial overlap between jellyfish and forage fish.
It is also possible that the change in mean overlap, as indicated by GIC (Fig. 5), was affected by variation in the vertical distribution of fish (or jellyfish), which would, in turn, affect their catchability by pelagic surface trawls. The vertical distributions of forage fish and C. melanaster may be affected by environmental conditions on both a seasonal and inter-annual basis. The collections in this study were made in the upper $20 \mathrm{~m}$ of the water column during the day in the boreal late summer and early fall, which would capture a substantial proportion of the C. melanaster population but miss some of the diel vertical migrants (Brodeur 1998, Decker et al. 2014). For the forage fishes, Parker-Stetter et al. (2013) examined the vertical distribution of capelin, age-0 pollock and Pacific cod from acoustic data and trawl collections from the BASIS surveys used in the present study and found that a sizeable proportion of the 

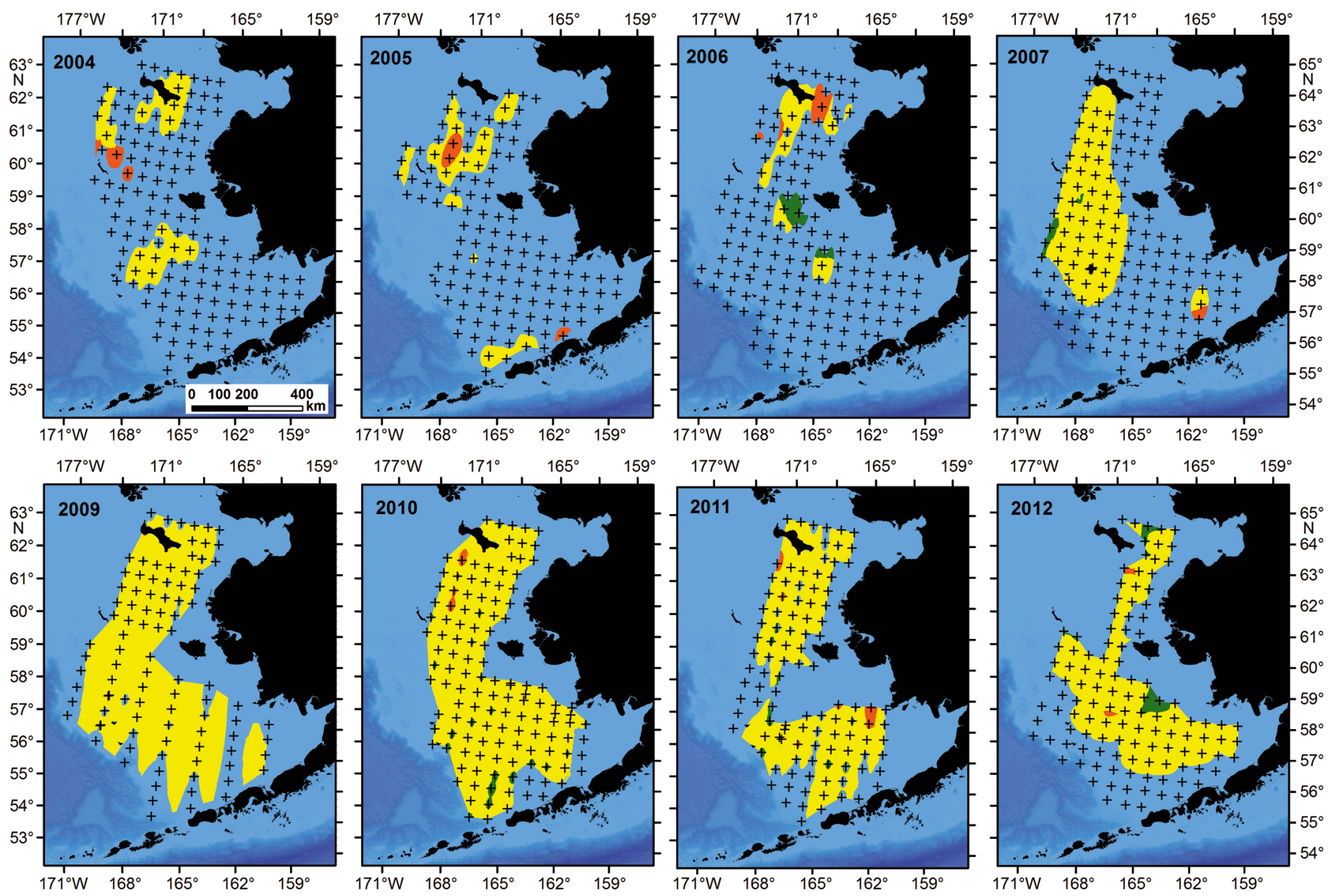

Fig. 8. Areas of no, medium and high overlap between Chrysaora melanaster and capelin Mallotus villosus. Shown are sampling stations (crosses), occurrence of capelin (green area), overlap between capelin and jellyfish (yellow area) and region of maximum overlap ( $>75$ th percentile of biomass of both capelin and jellyfish; red area)

population of all 3 species inhabited depths below those that were trawled, especially capelin. They also found substantial inter-annual variability depending on oceanographic changes in water column structure and mixed layer depth. The vertical distribution of age- 0 walleye pollock and presumably Pacific cod may change seasonally due to the autumn breakdown of the thermocline, when pollock undergo an ontogenetic movement to deeper layers (ParkerStetter et al. 2015). Given this information and also the differential catchability of jellyfish and forage species with the trawl used (e.g. De Robertis et al. 2017), our overlap measurements based on the abundance of the 2 groups should only be considered as approximate.

We observed that fish densities themselves changed between these 2 periods (Fig. 2b-e), and it is possible that during times of high jellyfish abundance, $C$. melanaster had a substantial predatory impact on the early life stages of these forage fish. However, to date we have no evidence that $C$. melanaster have a large predatory impact on fish larvae in the Bering Sea. Several of the diet studies on this species (Brodeur et al. 2002, Zavolokin et al. 2008, Decker et al. 2014) have shown evidence of feeding on younger stages of fish including walleye pollock, but these were conducted during the summer period whereas most fish spawn in late winter or spring in the Bering Sea. Thus, any estimates of the predatory effects of $C$. melanaster on Bering Sea fish larvae must await diet studies during the critical spring season and in larval rearing habitats.

Field and modeling studies in other ecosystems indicate that jellyfish can negatively impact fisheries because they have the potential to directly compete with zooplanktivorous fish, prey on fish eggs and 
Walleye pollock present Walleye pollock \& C. melanaster overlap Walleye pollock \& C. melanaster overlap (biomasses $\geq 75$ th quantile)
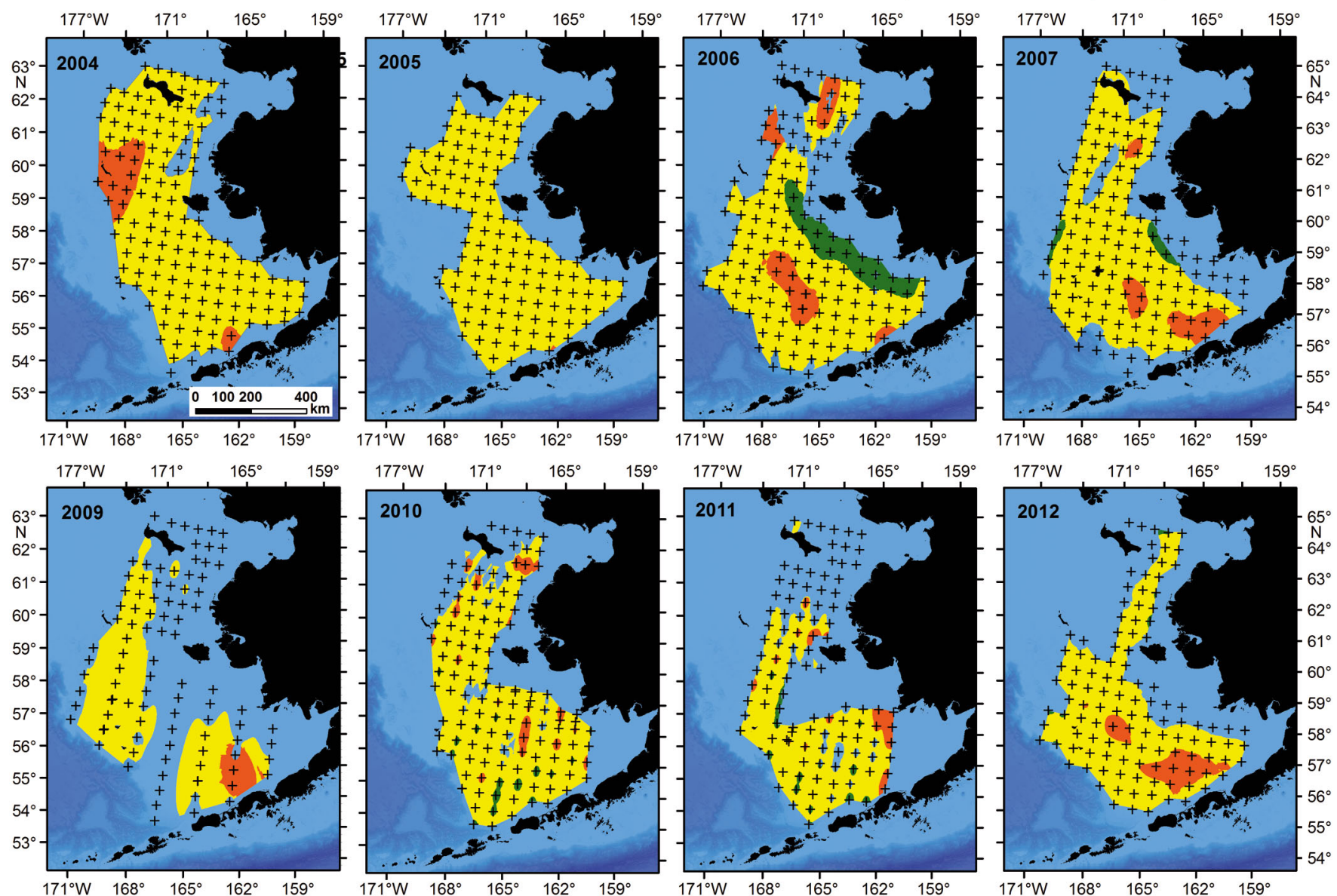

Fig. 9. Areas of no, medium and high overlap between Chrysaora melanaster and age-0 walleye pollock Gadus chalcogrammus. Shown are sampling stations (crosses), occurrence of pollock (green area), overlap between pollock and jellyfish (yellow area) and region of maximum overlap (> 75th percentile of biomass of both pollock and jellyfish; red area)

larvae, physically harm fish via stinging nematocysts and affect the food web as a whole by diverting plankton production away from upper trophic levels (Brodeur et al. 2008b, 2011, Ruzicka et al. 2012, Robinson et al. 2015). In the North Sea, there are inverse correlations between jellyfish biomass and Atlantic herring Clupea harengus recruitment. This may be attributed to predation upon larval herring or to competition with larval herring for zooplankton (Lynam et al. 2005). In the NCC, high local abundances of the jellyfish Chrysaora fuscesens are associated with poor feeding conditions for juvenile salmon Oncorhynchus spp., as evidenced by less food in salmon stomachs in the presence of jellyfish blooms (Ruzicka et al. 2016). Even smaller juvenile salmon do not themselves prey heavily upon zooplankton within the NCC. They prey upon small juvenile fishes, which in turn prey upon zooplankton (Daly et al. 2009). These examples indicate the im- portance of monitoring jellyfish populations in systems that support commercially important fish species (Brodeur et al. 2016).

Compared to other regions of the globe, the Bering Sea has been substantially less affected by humans, but we need to consider factors such as fishing, pollution and coastal development as drivers of forage fish and jellyfish population changes and the impacts that these population changes have upon the rest of the ecosystem (e.g. Greene et al. 2015). Because Bering Sea jellyfish populations fluctuate widely annually (Brodeur et al. 2008a, Decker et al. 2014) and because jellyfish blooms may be becoming larger and more frequent in some regions (Brotz et al. 2012, Condon et al. 2012, 2013), an understanding of the trophic roles of gelatinous predators is required for the successful management of not only the EBS ecosystem, but of marine ecosystems in general. 


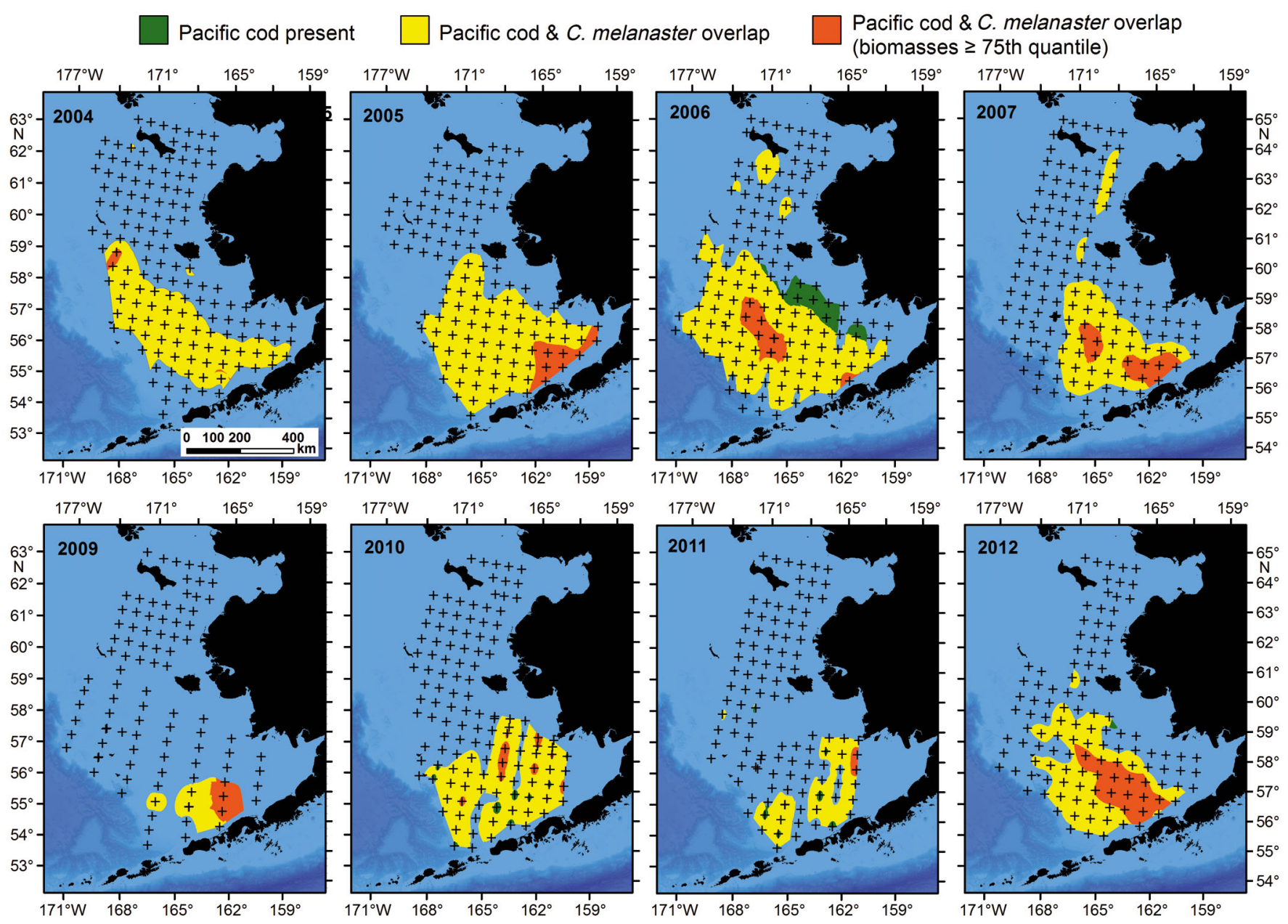

Fig. 10. Areas of no, medium and high overlap between Chrysaora melanaster and age-0 Pacific cod Gadus macrocephalus. Shown are sampling stations (crosses), occurrence of Pacific cod (green area), overlap between Pacific cod and jellyfish (yellow area) and region of maximum overlap ( $\geq 75$ th percentile of biomass of both Pacific cod and jellyfish; red area)

Acknowledgements. We thank the many scientists from AFSC/NOAA who collected the catch and environmental data used in this study. We acknowledge the support of the North Pacific Research Board (Project \#1405) and also the Lenfest Ocean Program funded by the Pew Charitable Trusts (Grant No. 00025535 to W. M. Graham at The University of Southern Mississippi).

\section{LITERATURE CITED}

Andrews AG III, Strasburger WW, Farley EV Jr, Murphy JM, Coyle KO (2016) Effects of warm and cold climate conditions on capelin (Mallotus villosus) and Pacific herring (Clupea pallasii) in the eastern Bering Sea. DeepSea Res II 134:235-246

* Aydin K, Mueter FJ (2007) The Bering Sea - a dynamic food web perspective. Deep-Sea Res II 54:2501-2525

Bez N, Rivoirard J (2000) Indices of collocation between populations. In: Checkley DM, Hunter JR, Motos L, van der Lingen CL (eds) Report of a workshop on the use of continuous underway fish egg sampler (CUFES) for mapping spawning habitat of pelagic fish. GLOBEC Report 14, GLOBEC International, Plymouth, p 48-52
*Bond NA, Adams JM (2002) Atmospheric forcing of the southeast Bering Sea shelf during 1995-99 in the context of a 40 -year historical record. Deep-Sea Res II 49: 5869-5887

Brodeur RD (1998) In situ observations of the association between juvenile fishes and scyphomedusae in the Bering Sea. Mar Ecol Prog Ser 163:11-20

Brodeur RD, Wilson MT, Walters GE, Melnikov IV (1999) Forage fishes in the Bering Sea: distribution, species associations, and biomass trends. In: Loughlin TR, Ohtani K (eds) Dynamics of the Bering Sea. University of Alaska Sea Grant, Fairbanks, AK, p 509-536

* Brodeur RD, Sugisaki H, Hunt GL Jr (2002) Increases in jellyfish biomass in the Bering Sea: implications for the ecosystem. Mar Ecol Prog Ser 233:89-103

* Brodeur RD, Decker MB, Ciannelli L, Purcell JE and others (2008a) Rise and fall of jellyfish in the eastern Bering Sea in relation to climate regime shifts. Prog Oceanogr 77: 103-111

* Brodeur RD, Suchman CL, Reese DC, Miller TW, Daly EA (2008b) Spatial overlap and trophic interactions between pelagic fish and large jellyfish in the northern California Current. Mar Biol 154:649-659 
Brodeur RD, Ruzicka JJ, Steele JH (2011) Investigating alternate trophic pathways through gelatinous zooplankton and planktivorous fishes in an upwelling ecosystem using end-to-end models. In: Omori K, Guo X, Yoshie N, Fujii N, Handoh IC, Isobe A, Tanabe S (eds) Interdisciplinary studies on environmental chemistry: marine environmental modeling and analysis. TERRAPUB, Tokyo, p 57-63

*Bodeur RD, Barceló C, Robinson KL, Daly EA, Ruzicka JJ (2014) Spatial overlap between forage fishes and the large medusa Chrysaora fuscescens in the northern California Current region. Mar Ecol Prog Ser 510:167-181

*Bodeur RD, Link JS, Smith BE, Ford MD, Kobayashi DR, Jones TT (2016) Ecological and economic consequences of ignoring jellyfish: a plea for increased monitoring of ecosystems. Fisheries 41:630-637

*Botz L, Cheung WWL, Kleisner K, Pakhomov E, Pauly D (2012) Increasing jellyfish populations: trends in large marine ecosystems. Hydrobiologia 690:3-20

* Chen K, Ciannelli L, Decker MB, Ladd C, Cheng W, Zhou Z, Chan KS (2014) Reconstructing source-sink dynamics in a population with a pelagic dispersal phase. PLOS ONE 9:e95316

Condon RH, Steinberg DK, Del Giorgio PA, Bouvier TC, Bronk DA, Graham WM, Ducklow HW (2011) Jellyfish blooms result in a major microbial respiratory sink of carbon in marine systems. Proc Natl Acad Sci USA 108: 10225-10230

Condon RH, Graham WM, Duarte CM, Pitt KA and others (2012) Questioning the rise of gelatinous zooplankton in the world's oceans. Bioscience 62:160-169

* Condon RH, Duarte CM, Pitt KA, Robinson KL and others (2013) Recurrent jellyfish blooms are a consequence of global oscillations. Proc Natl Acad Sci USA 110: 1000-1005

Coyle KO, Eisner LB, Mueter FJ, Pinchuk AI and others (2011) Climate change in the southeastern Bering Sea: impacts on pollock stocks and implications for the oscillating control hypothesis. Fish Oceanogr 20:139-156

* Daly EA, Brodeur RD, Weitkamp LA (2009) Ontogenetic shifts in diets of juvenile and subadult coho and Chinook salmon in coastal marine waters: Important for marine survival? Trans Am Fish Soc 138:1420-1438

De la Cruz M (2008) Metodos para analizar datos puntuales. In: Maestre FT, Escudero AY, Bonet A (eds) Introduccion al analisis espacial de datos en ecologia y ciencias ambientales: metodos y aplicaciones. Asociacion Espanola de Ecologia Terrestre, Universidad Rey Juan Carlos y Caja de Ahorros del Mediterraneo, Madrid, p 76-127

De Robertis A, Taylor K, Williams K, Wilson CD (2017) Species and size selectivity of two midwater trawls used in an acoustic survey of the Alaska Arctic. Deep-Sea Res II 135:40-50

Deason EE, Smayda TJ (1982) Experimental evaluation of herbivory in the ctenophore Mnemiopsis leidyi relevant to ctenophore-zooplankton-phytoplankton interactions in Narragansett Bay, Rhode Island, USA. J Plankton Res 4:219-236

Decker MB, Liu H, Ciannelli L, Ladd C, Cheng W, Chan KS (2013) Linking changes in eastern Bering Sea jellyfish populations to environmental factors via nonlinear time series models. Mar Ecol Prog Ser 494:179-189

Decker MB, Cieciel K, Zavolokin A, Lauth R, Brodeur RD, Coyle KO (2014) Population fluctuations of jellyfish in the Bering Sea and their ecological role in this productive shelf ecosystem. In: Pitt KA, Lucas CH (eds) Jellyfish blooms. Springer, Dordrecht, p 153-183

"Eisner LB, Napp JM, Mier KL, Pinchuk AI, Andrews AG III (2014) Climate-mediated changes in zooplankton community structure for the eastern Bering Sea. Deep-Sea Res II 109:157-171

KEriksen E (2016) Do scyphozoan jellyfish limit the habitat of pelagic species in the Barents Sea during the late feeding period? ICES J Mar Sci 73:217-226

Eriksen E, Prozorkevich D, Trofimov A, Howell D (2012) Biomass of scyphozoan jellyfish, and its spatial association with 0-group fish in the Barents Sea. PLOS ONE 7: e33050

* Graham WM, Gelcich S, Robinson KL, Duarte CM and others (2014) Linking human well-being and jellyfish: ecosystem services, impacts, and societal responses. Front Ecol Environ 12:515-523

Greene C, Kuehne L, Rice C, Fresh K, Pentilla D (2015) Forty years of change in forage fish and jellyfish abundance across greater Puget Sound, Washington (USA): anthropogenic and climate associations. Mar Ecol Prog Ser 525: $153-170$

Hollowed AB, Barbeaux SJ, Cokelet ED, Farley E and others (2012) Effects of climate variations on pelagic ocean habitats and their role in structuring forage fish distributions in the Bering Sea. Deep-Sea Res II 65-70:230-250

*Hunt GL Jr, Stabeno P, Walters G, Sinclair E, Brodeur RD, Napp JM, Bond NA (2002) Climate change and control of the southeastern Bering Sea pelagic ecosystem. DeepSea Res II 49:5821-5853

*Hunt GL Jr, Coyle KO, Eisner LB, Farley EV and others (2011) Climate impacts on eastern Bering Sea foodwebs: a synthesis of new data and an assessment of the oscillating control hypothesis. ICES J Mar Sci 68:1230-1243

*Hurst TP, Moss JH, Miller JA (2012) Distributional patterns of 0-group Pacific cod (Gadus macrocephalus) in the eastern Bering Sea under variable recruitment and thermal conditions. ICES J Mar Sci 69:163-174

Johnston K, Ver Hoef JM, Krivoruchko K, Lucas N (2001) Using ArcGIS Geostatistical Analyst. ESRI, Redlands, CA

Kim DH, Seo JN, Yoon W, Suh YS (2012) Estimating the economic damage caused by jellyfish to fisheries in Korea. Fish Sci 78:1147-1152

Lynam CP, Heath MR, Hay SJ, Brierley AS (2005) Evidence for impacts by jellyfish on North Sea herring recruitment. Mar Ecol Prog Ser 298:157-167

* Möller H (1984) Reduction of a larval herring population by jellyfish predator. Science 224:621-622

Mueter FJ, Litzow MA (2008) Sea ice retreat alters the biogeography of the Bering Sea continental shelf. Ecol Appl 18:309-320

Oguz T, Fach B, Salihoglu B (2008) Invasion dynamics of the alien ctenophore Mnemiopsis leidyi and its impact on anchovy collapse in the Black Sea. J Plankton Res 30: 1385-1397

*Parker-Stetter SL, Horne JK, Farley EV, Barbee DH, Andrews AG III, Eisner LB, Nomura JM (2013) Summer distributions of forage fish in the eastern Bering Sea. Deep-Sea Res II 94:211-230

*Parker-Stetter SL, Horne JK, Urmy S, Heintz RA, Eisner L, Farley E (2015) Vertical distribution of age-0 walleye pollock during late summer: Environment or ontogeny? Mar Coast Fish 7:349-369

* Parker-Stetter S, Urmy S, Horne J, Eisner L, Farley E (2016) Factors affecting summer distributions of Bering Sea for- 
age fish species: assessing competing hypotheses. DeepSea Res II 134:255-269

Pennington M (1996) Estimating the mean and variance from highly skewed marine data. Fish Bull 94:498-505

Purcell JE, Arai MN (2001) Interactions of pelagic cnidarians and ctenophores with fish: a review. Hydrobiologia 451: $27-44$

Purcell JE, Grover JJ (1990) Predation and food limitation as causes of mortality in larval herring at a spawning ground in British Columbia. Mar Ecol Prog Ser 59:55-61

Purcell JE, Sturdevant MV (2001) Prey selection and dietary overlap among zooplanktivorous jellyfish and juvenile fishes in Prince William Sound, Alaska. Mar Ecol Prog Ser 210:67-83

Purcell JE, Uye SI, Lo WT (2007) Anthropogenic causes of jellyfish blooms and their direct consequences for humans: a review. Mar Ecol Prog Ser 350:153-174

Quiñones J, Monroy A, Acha EM, Mianzan H (2013) Jellyfish bycatch diminishes profit in an anchovy fishery off Peru. Fish Res 139:47-50

R Core Team (2013) R: a language and environment for statistical computing. R Foundation for Statistical Computing, Vienna

Robinson KL, Ruzicka JJ, Decker MB, Brodeur RD and others (2014) Jellyfish, forage fish and the world's major fisheries. Oceanography (Wash DC) 27:104-115

Robinson KL, Ruzicka JJ, Hernandez FJ, Graham WM, Decker MB, Brodeur RD, Sutor M (2015) Evaluating energy flows through jellyfish and gulf menhaden (Brevoortia patronus) and the effects of fishing on the northern Gulf of Mexico ecosystem. ICES J Mar Sci 72: 2301-2312

Ruzicka JJ, Brodeur RD, Emmett RL, Steele JH and others (2012) Interannual variability in the Northern California Current food web structure: changes in energy flow pathways and the role of forage fish, euphausiids, and jellyfish. Prog Oceanogr 102:19-41

Ruzicka JJ, Daly EA, Brodeur RD (2016) Evidence that summer jellyfish blooms impact Pacific Northwest salmon production. Ecosphere 7:e01324

Schnedler-Meyer NA, Mariani P, Kiørboe T (2016) The global susceptibility of coastal forage fish to competition by large jellyfish. Proc Biol Sci 283:20161931

Shoji J, Mizuno KI, Yamamoto M, Miller TW, Hamaoka H, Omori K (2009) Spatial distribution and dietary overlap

Editorial responsibility: John Costello (Guest Editor), Providence, Rhode Island, USA between Japanese anchovy Engraulis japonicus and moon jellyfish Aurelia aurita in the Seto Inland Sea, Japan. Sci Mar 73:191-198

* Sigler MF, Napp JM, Stabeno PJ, Heintz RA, Lomas MW, Hunt GL Jr (2016) Variation in annual production of copepods, euphausiids, and juvenile walleye pollock in the southeastern Bering Sea. Deep-Sea Res II 134: 223-234

Stabeno PJ, Kachel NB, Moore SE, Napp JM, Sigler M, Yamaguchi A, Zerbini AN (2012) Comparison of warm and cold years on the southeastern Bering Sea shelf and some implications for the ecosystem. Deep-Sea Res II 65-70:31-45

Stabeno PJ, Danielson SL, Kachel DG, Kachel NB, Mordy CW (2016) Currents and transport on the eastern Bering Sea shelf: an integration of over 20 years of data. DeepSea Res II 134:13-29

Strasburger WW, Hillgruber N, Pinchuk A, Mueter FJ (2014) Feeding ecology of age-0 walleye pollock (Gadus chalcogrammus) and Pacific cod (Gadus macrocephalus) in the southeastern Bering Sea. Deep-Sea Res II 109: $172-180$

Suchman CL, Daly EA, Keister JE, Peterson WT, Brodeur RD (2008) Feeding patterns and predation potential of scyphomedusae in a highly productive upwelling region. Mar Ecol Prog Ser 358:161-172

Syrjala SE (1996) A statistical test for a difference between the spatial distribution of two populations. Ecology 77 : $75-80$

* Tilves U, Purcell JE, Fuentes VL, Torrents A and others (2016) Natural diet and predation impacts of Pelagia noctiluca on fish eggs and larvae in the NW Mediterranean. J Plankton Res 38:1243-1254

Woillez M, Poulard JC, Rivoirard J, Petitgas P, Bez N (2007) Indices for capturing spatial patterns and their evolution in time, with application to European hake (Merluccius merluccius) in the Bay of Biscay. ICES J Mar Sci 64: $537-550$

Woillez M, Rivoirard J, Petitgas P (2009) Notes on survey based spatial indicators for monitoring fish populations. Aquat Living Resour 22:155-164

* Zavolokin AV, Glebov II, Kosenok NS (2008) Distribution, quantitative composition, and feeding of jellyfish in the western Bering Sea in summer and fall. Russ J Mar Biol 34:461-467

Submitted: February 1, 2017; Accepted: July 24, 2017

Proofs received from author(s): September 23, 2017 